\title{
Raft Forming System - Gastroretentive drug delivery system
}

\author{
Rohith Patel, Geethika Vaishnav
}

Acropolis Institute of Pharmaceutical Education and Research, Indore

Received: 16 Nov 2020; Received in revised form: 07 Dec 2020; Accepted: 15 Dec 2020; Available online: 21 Dec 2020

(C)2020 The Author(s). Published by Infogain Publication. This is an open access article under the CC BY license

(https://creativecommons.org/licenses/by/4.0/).

\begin{abstract}
In the recent times several studies and research have been conducted on drug delivery system through mouth in order to overcome several problems like emptying time and gastric retention. Taking medication through mouth is the preferable way compared to others, because of easiness in taking medication and compliance of patients. Limited gastric residence time is the limitation of taking medication orally. In order to increase this gastric retention time, several methods have been proposed. This article focuses on floating drug delivery system to overcome the difficulties associated with design of formulation. Advances and highlights of the floating raft system has been reviewed in this article. Formulation, mechanism, and development of raft forming system is also reviewed in this article.
\end{abstract}

Keywords - Raft Forming System, Drug Delivery System, Human Stomach.

\section{INTRODUCTION}

In our stomach the medicine we take are sometimes poorly soluble or unstable in fluids of intestine. Raft forming system, is a type of floating drug delivery system, remains and helps drugs that are poorly soluble in stomach. Let us discuss more about the needs of Gastroretentive Drug Delivery System [1]. Oral delivery of medication is widely used in pharmacy field in order to treat diseases, but this conventional method of delivery has major drawbacks, where some of the drugs are gets absorbed at a specific rate and site only. Now a day's pharmacy filed is focusing on drugs that will require specificity of site. To deliver drugs at intestine or stomach, one of the site-specific delivery is Gastro -retentive delivery. Site specificity is obtained by controlled delivery of drugs in stomach and intestine. Floating drug delivery system will have high density than stomach fluids, so remain same for a longer period of time without affecting the gastric emptying rate. The drug will slowly be released, at the required rate while system floats on the gastric contents. The residue is emptied from stomach after the release of the drug, which results in proper control of fluctuation in plasma concentration and increased gastric residence time [2]. Some of the potential situations or candidates for gastroretentive drug delivery systems are, Drugs that are degradable in colon like Metformin HCL, Drugs that are poorly soluble in Alkaline like Diazepam, Drugs acting locally in the stomach [3], Drugs that are absorbed in stomach like Amoxicillin [4].More than half of the total percentage of available drug delivery systems are administered through mouth, as this is the promising drug delivery system route and based on factors like emptying process and time its effective than others.

\section{Anatomy of gastrointestinal tract:}

The gastrointestinal tract can be divided into three regions:

1. Stomach

2. Small intestine- Duodenum, Jejunum and Ileum

3. Large intestine

Gasterointestinal tract consists of hallow tube which is muscular and it starts from oral cavity where food enters our body continue through pharynx, oesophagus, stomach, intestines to the rectum and anus, and this is where food is expelled. There are multiple organs that help absorb nutrients from the food and secrete the enzymes. Gastric physiology and gastric motility understanding is necessary to understand 
the approaches for gastro retention, which is the first concept of floating drug delivery system cultured by Davis in 1968.Human stomach when its at rest has a volume of 25 to $50 \mathrm{ml}$ volume, which can expand upto $1500 \mathrm{ml}$ after having a meal. Below the diaphragm, on the left-hand portion of the abdomen, stomach is located and looks like $\mathbf{J}$ shape. left side of hypochondriac and portion of epigastric is occupied by stomach. Stomach functionality is primarily to hold the food in it temporarily and grind the food and release it into duodenum. It will be helpful to develop dosage form that will reside in small intestine, as drugs are absorbed in there.

In classical anatomy human stomach is divided into 4 sections starting at the cardia [5].

- The section where esophagus empty the contents into stomach is called Cardia [6].

- The curved part which is on the upper side is called fundus.

- The main central part of stomach is called body.

- The section of the stomach which is on the lower side empties contents into duodenum is called pylorus.

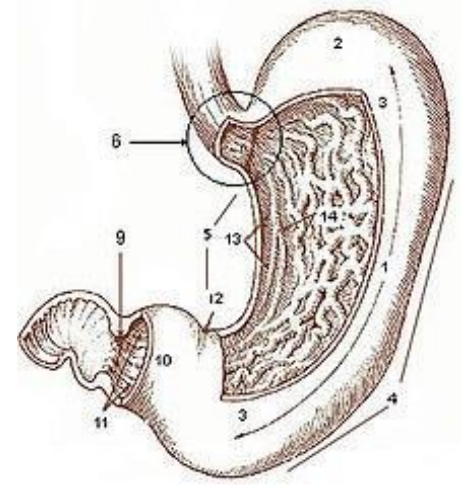

Fig. 1 Anatomy of Human Stomach

1. Body of stomach 2. Fundus 3. Anterior wall 4. Greater curvature 5. Lesser curvature 6. Cardia 9. Pyloric sphincter 10. Pyloric antrum 11. Pyloric canal 12. Angular incisure 13. Gastric canal 14. Rugae [6].

The region following the "z-line" of the gastroesophageal junction, is defined as Cardia. Epithelium changes from stratified squamous to columnar happens at this point. Oesophageal sphincter is near to Cardia [6]. Cardia is the region of oesophageal lining and recent studies proved that cardia is not distinct part of stomach.
Fundus: This lie above the horizontal plane which passes through cardiac orifice and is a superior part of stomach.

Body: This part lies between Fundus and Antrum and is central part of stomach and is also largest part of stomach.

Antrum: This lie to right of the angular notch in the imaginary transpyloric plane and on the right joins the pyloric canal. Body and Fundus main function is storage and for Antrum it is grinding and mixing. Gastric contents are exerted pressure by the fundus and sent them toward the distal stomach. Particles need to be of size 1-2 $\mathrm{mm}$ in order to pass through pyloric valve. Stomach has limitation -short residence time $[9,10,11,12]$.

Float Rafting system Design: There are several factors to be considered to formulate a raft forming system and they are like drug molecule and its physicochemical properties, and one who is diseased and condition of he/she, preference of marketing and population of the patients etc., When we consider physicochemical properties they are like molecular charge, molecular weight, lipophilicity. The factors for formulation need to be considered are osmolarity, temperature, viscosity and spreadability. For the dosage form, to achieve gastric retention of, it needs to be able to satisfy below criteria:

1. The release of drug should be slow from the system

2. Compliance of patient should be good

3. Specific gravity should be maintained lower than gastric contents

4. For the force exerted by peristaltic waves in the stomach and griding, churning moments, and contraction, the dosage form needs to be able to withstand the force.

5. The device should easily exit out of the system, after the drug is released $[13,14,15,16]$

\section{Raft system formulation and the ingredients used:}

For controlled release of gastric retention, we should select appropriate person for the formulation, and the ingredients used for the formulation are carbonates or alkaline carbonates, gel forming agent, which can cooperate to the formation of less dense system and is able to float on the gastric fluids [17].

\section{Raft system and the Drugs Selection Criteria:}

For disorders and gastrointestinal infections, to deliver the antacids, raft forming system has gained lot of attention. For esophagitis and heartburn raft forming system is the potential approach. For the drugs that are not stable in intestine or poorly soluble, this system is suitable. For antacids the drugs 
that re used are magnesium hydroxide, Aluminum hydroxide, aluminum phosphate, calcium carbonate. For $\mathrm{h}_{2}$ RECEPTOR the drugs used are loxatidine, famotidine, nizatidine, Omeprazole, lansoprazole, pantoprazole, Cimetidine, ranitidine. For helicobacter pylori the drugs used are Amoxicillin [4], clarithromycin, tetracycline, metronidazole etc.,

For gastro retention, criteria for drug selection are as follows:

1. Primarily absorbed drugs in the stomach like amoxicillin

2. Antacid drugs that are acting locally in stomach for helicobacter pylori

3. At Alkaline $\mathrm{pH}$, drugs that are poorly soluble like Diazepam.

4. From the GI tract drugs that are rapidly absorbed $[18,19,20,21,22]$

5. Drugs which has window of absorption as narrow.

For gastro retention, criteria for drug that are not suitable are as follows:

1. Drugs that are used for selective release in the colon

2. If acid solubility is limited for the drugs, then they are not helpful

3. In the gastric environment if the drug has instability, it will not fit.

\section{Raft system and the Polymer Used for Formulation:}

In the stomach, which is gastrointestinal tract, to deliver the drug various polymers are employed in floating drug delivery system. IN the formation of the raft forming drug system various natural and synthetic polymers are used. Some of the natural polymers are gellan gum, alginic gum, guar gum etc.., and some of the synthetic polymers are HPMC, poly (DLlactide-co-glycolide) and poly-caprolactone etc.,

In situ gels the polymers used should have the following characteristics:

1. Biocompatibility should exist.

2. pseudoplastic behavior should be there.

3. Along with increase in shear rate polymer should be capable of increasing viscosity.

\section{Some of the polymers used for raft forming system:}

\section{Sodium alginate:}

Sodium alginate is available naturally and is widely used polymer in Raft Forming system. In chemical terms it is alginic acid salt, consisting of $\mathrm{D}$ mannuronic and Lglucuronic acid residues connected by 1,4- glycosidic. The alginates solution form firm gels when di or trivalent ions are present for example like magnesium ions. Sodium alginate salt which is formed from alginate salt is used for preparing gel forming solution. Due to the nature of alginate salts which are nontoxic in nature and biodegradable they are most considered. They also have bio adhesive property.

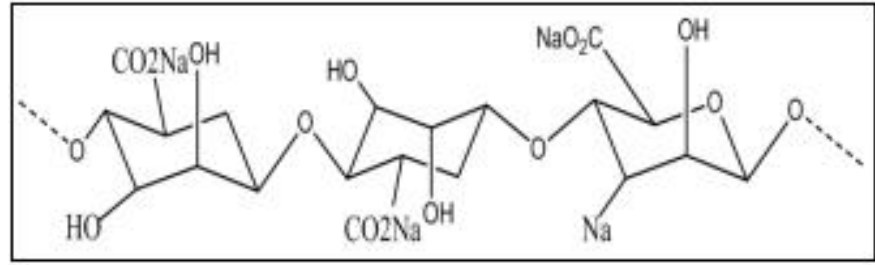

Fig. 2 Chemical structure of Sodium Alginate

\section{Pectin:}

These are originated from plant which has anionic characteristics and can be divided into two polysaccharides and contain residues of -(1-4) -D-galacturonic acid. In the presence of medium it can for gel, and as till gel formation is possible. Pectin usually forms at $\mathrm{pH}$ less than 3.5 and it is a complex polysaccharide which comprise of D-galacturonic acid residues in an a-(1-4) chain.

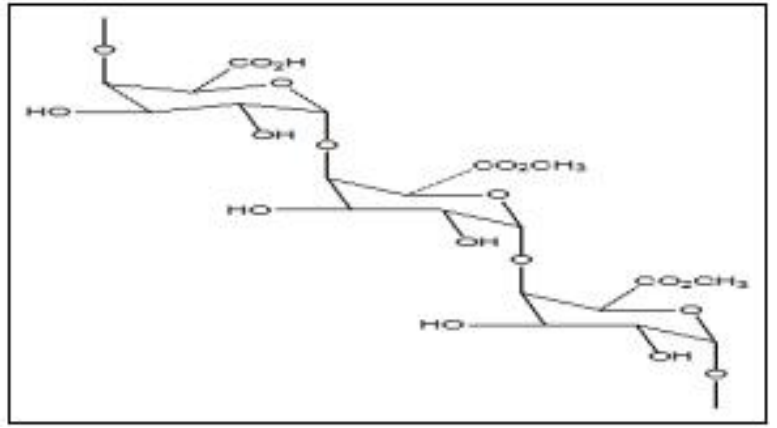

Fig. 3 Chemical structure of pectin

\section{Floating Raft Forming System- Advantages:}

1. Therapeutic efficacy will improve.

2. Floating of dosage forms faster than others.

3. Administration into the patient is easy.

4. It is proved more effective because on gastric contents it forms low density viscous layer.

5. Plasma level fluctuation will reduce.

6. In the small intestinal region, the absorption of the drug is narrow like delivery of drugs. 
7. Drug delivery system specific to stomach can be targeted like H. pylori-induced gastric ulcer $[23,24,25,26]$.

\section{Limitations of Float Raft forming system:}

1. The formulation is done in the form of solutions, and it is susceptible to stability problems due to microbial degradation.

2. The stability problem can also be cause if the formulation is poorly stored. This is because if the formulation is stored for a long time $\mathrm{pH}$ might change or due to inappropriate temperature situations.

3. Gel formation is possible if polymer is exposed to radiations like UV, electromagnetic etc.,[28].

\section{CONCLUSION}

Raft Forming System which is Gastroretentive drug delivery system is designed in order to increase this gastric retention time, some of the problems we have with other methods of taking medication, as therapeutic efficacy will improve, floating of dosage forms faster than others administration into the patient is easy.

And so a floating Raft System which is promising has been figured out and achieved which might be suitable for some of the population like pediatrics and other people who has difficulty in taking controlled medication solid forms and this could lead to efficacy enhanced patient compliance.

\section{REFERENCES}

[1] Subhramananyam CVS, Setty JT. Laboratory manual of physical pharmaceutics. Vallabh prakashan 2002; page no21

[2] Shah P, Bhimani B and Patel U: Brief review of polymers use in raft forming system. Inter $\mathbf{J}$ of Pharmaceutical Research \& Bioscience 2014; 3(5): 437-48

[3] MathurP, Saroha K, Syan N, Verma S and Kumar V. Floating drug delivery system: An innovative acceptable approach in gastro retentive drug delivery. Scholars research library 2010; 2:257-2704.

[4] Akhil Kamsali, Bhargav Eranti, Mounika CH, Ravi Manne, Chaitanya Barghav G, Subba Reddy P, (2020),"Development and Optimization of Amoxicillin Floating Raft System to effectively treat Helicobacter pylori infection", Ars Pharmaceutica, ISSN: 2340-9894,Vol.61,Issue 3,pp.1-6, Editorial Universidad de Granada. http://dx.doi.org/10.30827/ars.v61i3.13718

[5] Anatomy photo:37:06-0103 at the SUNY Downstate Medical Center - "Abdominal Cavity: The Stomach"
[6] Brunicardi, F. Charles; Andersen, Dana K.; et al., eds. (2010). Schwartz's principles of surgery (9th ed.). New York: McGraw-Hill, Medical Pub. Division. ISBN 978-0071547703.

[7] https://en.wikipedia.org/wiki/Stomach\#cite_noteSCHWARTZ2010-8

[8] Lenglinger, J.; et al. (2012). "The cardia: esophageal or gastric? Critical reviewing the anatomy and histopathology of the esophagogastric junction". Acta Chir Iugosl. 59 (3): 15-26. doi:10.2298/ACI1203015L. PMID 23654002

[9] Tortora GH and Derrickson B: Principle of anatomy and physiology, Wiley International, Edition 11th, 902-940.

[10] Brahmankar DM and Jaiswal SB: Biopharmaceutics and pharmacokinetics- A Treatise. Vallabh Prakashan, Edition 2 nd , 2009; 63-71

[11] Jain NK: Progress in controlled and drug delivery system. CBS Publishers and Distributers Pvt., Ltd., 76-97.

[12] Ross and Wilson: Anatomy and physiology in heath and illness, Edition 12th, 294-308.

[13] Doshi N: In situ gel: a novel approach of gastro retentive drug delivery. Asian Journal of Pharmaceutical Sciences and Research 2013; 3(3).

[14] Vishvadeep P, Akshay P, Henil P, Jay P, Ravi P and Upendra P: A review on in-situ gelling system: Novel approach for stomach specific drug delivery. International Journal of Pharmaceutical Research and Bioscience 2014; 3(2): 466-480

[15] Bhavsar DN, Varde NM, Sini S, Shah VH and Upadhyay UM: Advances in GRDDS: Raft forming system a review.Journal of Drug Delivery and Therapeutics 2012; 2(5):123-28.

[16] Samar ES: Floating systems for oral controlled release drug delivery. PhD Theses, Pharmazie der Freien Universität Berlin, Juli 2010; 1-95.

[17] Vipul D, Prajapati, Girish K, Tohra AK and Bhumi SZ: Raft forming system-an upcoming approach of gastroretentive drug delivery system. Elsevier, Journal of Controlled Release 2013; 168: 151-165.

[18] Jayswal B, Yadav V, Patel K, Patel B and Patel P: Formulation and evaluation of floating in-situ gel based gastro retentive drug delivery of cimetidine. International J for Pharmaceutical Res Scholars 2012; 1(2); 327-337. 17.

[19] Sanket C, Dron M, Ravi P, Jay P, Rahul D and Sunita C: Formulation and evaluation of floatable in-situ gel for stomach-specific drug delivery of ofloxacin. American Journal of Advanced Drug Delivery 2013; 1(3): 285-299. 18.

[20] Rishad R, Chhagan N, Dashrath M and Nurudin P: Development of a novel floating in-situ gelling system for stomach specific drug delivery of the narrow absorption window drug baclofen. Iranian Journal of Pharmaceutical Research 2010; 9(4): 359-368

[21] Singh A, Dubey V and Arora V: Role of natural polymers used in floating drug delivery system. Journal of Pharmaceutical and Scientific Innovation 2012; 11-15. 
[22] Nirmal HB, Bakliwal SP and Pawar SP: In-situ gel: new trends in controlled and sustained drug delivery system. Inter $\mathbf{J}$ of Pharm Tech Research 2010; 2(2): 1398-1408.

[23] Doshi N: In situ gel: a novel approach of gastro retentive drug delivery. Asian Journal of Pharmaceutical Sciences and Research 2013; 3(3).

[24] Bhavsar DN, Varde NM, Sini S, Shah VH and Upadhyay UM: Advances in GRDDS: Raft forming system a review. Journal of Drug Delivery and Therapeutics 2012; 2(5): 123-28

[25] Samar ES: Floating systems for oral controlled release drug delivery. PhD Theses, Pharmazie der Freien Universität Berlin, Juli 2010; 1-95

[26] Nikita D: Floating drug delivery system. Journal of Current Pharmaceutical Research 2011; 7(1): 6-20

[27] Raut SS and Shinde HA: In-situ raft forming system: a review. Int J Pharmacognosy 2018; 5(6): 337-49. doi link: http://dx.doi.org/ 10.13040/IJPSR.0975-8232.IJP.5(6).337-49

[28] Sathish D, Himabhindu S, Shravan K and Rao Y: Floating drug delivery system for prolonged gastric residence time: A review. Current Drug Delivery 2011; 8: 494-510

[29] Kamsali, Akhil; et al. Development and Optimization of Amoxicillin Floating Raft System to effectively treat Helicobacter pylori infection. Ars Pharm, 61(3): 163-168 (2020) [doi:http://dx.doi.org/10.30827/ars.v61i3.13718]

[30] https://kids.kiddle.co/Stomach 